\title{
La Pandemia de COVID-19 en el ámbito laboral: realidad y posibles soluciones en México
}

\section{The COVID-19 pandemic in the workplace: reality and possible solutions in Mexico}

Verónica Lidia MartínEz MartíneZ

$0^{\circ}$ IUS Comitiãlis / Año 3, Número 6 / julio - diciembre 2020 / pp. 213-238 / ISSN: 2594-1356 Recepción: 10 de julio de 2020 / Aceptación: 11 de octubre de 2020

Resumen: Partiendo de una breve referencia a los acuerdos publicados por la autoridad sanitaria que consignan las distintas acciones encaminadas a mitigar y controlar la pandemia del SARS-CoV2, en este trabajo se da cuenta de los principales efectos que han provocado esas acciones en el mundo del trabajo y de las posibles soluciones que se han planteado para contrarrestar las adversidades.

Palabras clave: COVID-19, laboral, empleo, grupos vulnerables, medidas.

Abstract: Based on a brief reference to the agreements published by the health authority that record the different actions aimed at mitigating and controlling the SARS-CoV2 pandemic, this paper reports on the main effects that these actions have caused in the world of work. and of the possible solutions that have been proposed to counteract adversity.

Key words: COVID-19, labor, employment, vulnerable groups, measures.

${ }^{1}$ Doctora en derecho con Mención Honorífica. Investigadora Nacional del Sistema Nacional de Investigadores del CONACyT. Profesora-Investigadora de la Universidad Anáhuac. México. 


\section{INTRODUCCIÓN}

El virus SARS-CoV2 (COVID-19) ha desencadenado una serie de repercusiones en el plano laboral, siendo de las más azarosas, el cierre de centros de trabajo, la pérdida de empleos e ingresos para los trabajadores que generan la disminución del consumo de bienes y servicios, dichas repercusiones son negativas para la actividad empresarial y la recuperación económica.

El objetivo de este trabajo es dar a conocer qué efectos ha provocado la actual pandemia en el ámbito laboral en México, con base en datos estadísticos de diversos organismos internacionales e instituciones nacionales. Bajo este tenor haciendo uso del método analítico, en primer lugar, se hace una breve referencia a los acuerdos publicados por la autoridad sanitaria para combatir la pandemia y procurar la salud de los mexicanos; en segundo lugar, los efectos que provoca el decreto de una emergencia sanitaria por causas de fuerza mayor, así como el impacto que han provocado en el mundo del trabajo las acciones consignadas en los acuerdos dictados, esto, sin dejar de lado, el dar a conocer las posibles soluciones para asegurar el trabajo, soslayar el desempleo y subempleo, así como impedir la transgresión del derecho al trabajo, por lo que en este esfuerzo se empleó el método comparado y fue necesaria la consulta de las recomendaciones e iniciativas propuestas por lo organismos internacionales especializados en materia de derechos humanos y los legisladores mexicanos, respectivamente.

\section{LA PANDEMIA DE COVID-19 COMO EMERGENCIA SANITARIA}

El 31 de diciembre de 2019 se registró un nuevo coronavirus denominado SARS-CoV2 (COVID-19) en la Ciudad de Wuhan (China), que ante su propagación e incremento de casos se le atribuye el carácter de pandemia. En México el primer caso por COVID-19 tuvo lugar el 27 de febrero de 2020 y ante la propagación del virus la Organización Mundial de la Salud (OMS) declaró que el 23 de marzo de 2020 iniciaba la fase 2, considerada como de transmisión local; el Plan de Atención Médica, la Jornada Nacional de Sana Distancia, el Plan de Defensa Nacional número III (Plan DN-III) fueron algunas de las acciones tendientes a mitigar y controlar la pandemia con la finalidad de proteger la salud de los mexicanos.

Debido a la pandemia, el Consejo de Salubridad General declaró el 30 de marzo de 2020 la emergencia sanitaria por causa de fuerza mayor. De acuerdo con la fracción I del artículo 427 de la Ley Federal del Trabajo, la fuerza mayor, sin la referencia a la emergencia sanitaria, es una de las causales de la suspensión de las relaciones laborales a la que puede conceptualizarse como la interrupción temporal de la presta- 
ción de servicios personales subordinados por parte del trabajador y del pago del salario (Areguin, 2019). Por supuesto, que dicha causal difiere de la contingencia sanitaria prevista en la fracción VII del mismo numeral.

En el nivel de la racionalidad lingüística o conceptual, la contingencia sanitaria es la posibilidad o riesgo que tiene un país, estado o municipio de llegar a enfrentar un problema de salud pública, provocado por epidemias, pandemias, invasión de enfermedades transmisibles o accidentes, que de presentarse puede convertirse, ante la gravedad y magnitud que represente el problema para la salud pública, en una situación de emergencia sanitaria, obligando a las autoridades a prepararse, diseñando las acciones, medidas y planes estratégicos para en caso de ser necesario poder implementarlos de inmediato. En tanto que la emergencia sanitaria es una situación de peligro real, existente, provocada por epidemias, pandemias, invasión de enfermedades transmisibles o accidentes, que obligan al aparato gubernamental de un país, estado o municipio, a tomar acciones inmediatas para preservar la salud de los habitantes (Pasco, 1997)

Además de las diferencias en el nivel de la racionalidad lingüística o conceptual también las consecuencias legales son distintas, la suspensión de las relaciones laborales por fuerza mayor sólo tendrá lugar cuando el Tribunal Laboral la apruebe a través del procedimiento especial colectivo; de acuerdo con el artículo 430 de la Ley Federal el Trabajo, ante la procedencia de la suspensión, los trabajadores tendrán derecho a percibir una indemnización, cuya cuantía dependerá del tiempo probable de suspensión de los trabajos y la posibilidad de que encuentren nueva ocupación, sin que pueda exceder del importe de un mes de salario.

Cuando la suspensión concluya, es obligación del empleador anunciar, con toda oportunidad, a aquéllos que prestaban sus servicios en la empresa, cuando tendrá lugar la reanudación de las labores para que sean repuestos en los puestos que ocupaban, siempre que se presenten a trabajar dentro del plazo establecido, que en ningún caso podrá ser menor de treinta días, computado a partir de la fecha del último llamado.

Mientras que al decretarse la contingencia sanitaria por parte de la autoridad competente, la suspensión temporal de labores opera de manera inmediata, no se requiere aprobación de parte de la autoridad laboral. Bajo este supuesto, el empleador deberá cubrir a sus trabajadores la indemnización equivalente a un día de salario mínimo general vigente, por cada día que dure la suspensión, sin que pueda exceder de un mes. Las labores se reanudarán al concluir la contingencia.

El 31 de marzo de 2020 se publicó en el Diario oficial de la Federación (DOF) el Acuerdo por el que se establecen acciones extraordinarias para atender la emergencia sanitaria generada por el virus SARS-CoV2, que distingue dos tipos de actividades productivas: las no esenciales y las esenciales. Por lo que respecta al primer tipo de actividades, en algunos casos, el teletrabajo ha sido una de las opciones para seguir laborando y percibir sus ingresos. Dentro del segundo tipo de actividades se consideraron a las siguientes: 
a. Las necesarias para atender la emergencia sanitaria. Dentro de este rubro se encuentran las actividades laborales de la rama médica, paramédica, administrativa y de apoyo en todo el Sistema Nacional de Salud, así como los que participan en su abasto, servicios y proveeduría, entre las que destacan el sector farmacéutico, en su producción y en la distribución (farmacias); la manufactura de insumos, equipamiento médico y tecnologías para la atención de la salud; los referentes a la disposición de los residuos peligrosos biológicos-infecciosos (RPBI), así como la limpieza y sanitización de las unidades médicas en los diferentes niveles de atención;

b. Las involucradas en la seguridad pública y la protección ciudadana; en la defensa de la integridad y la soberanía nacional; la procuración e impartición de justicia; así como la actividad legislativa en los niveles federal y estatal;

c. Los sectores fundamentales de la economía: Dentro de este apartado se encuentran los servicios financieros, la recaudación tributaria, la distribución y venta de energéticos, gasolineras y gas, la generación y distribución de agua potable, la industria de alimentos y bebidas no alcohólicas, mercados de alimentos, supermercados, tiendas de autoservicio, abarrotes y venta de alimentos preparados; servicios de transporte de pasajeros y de carga; producción agrícola, pesquera y pecuaria, agroindustria, industria química, productos de limpieza; ferreterías, servicios de mensajería, guardias en labores de seguridad privada; guarderías y estancias infantiles, asilos y estancias para personas adultas mayores, refugios y centros de atención a mujeres víctimas de violencia, sus hijas e hijos; telecomunicaciones y medios de información; servicios privados de emergencia, servicios funerarios y de inhumación, servicios de almacenamiento y cadena de frío de insumos esenciales; logística (aeropuertos, puertos y ferrocarriles), así como actividades cuya suspensión pueda tener efectos irreversibles para su continuación;

d. Las vinculadas de manera directa con la operación de los programas sociales gubernamentales, $\mathrm{y}$

e. Las necesarias para la conservación, mantenimiento y reparación de la infraestructura crítica que asegure la producción y distribución de servicios indispensables; como agua potable, energía eléctrica, gas, petróleo, gasolina, turbosina, saneamiento básico, transporte público, infraestructura hospitalaria y médica, entre otros más que pudieran listarse en este rubro.

Respecto de las actividades esenciales los trabajadores continúan con sus labores de manera presencial o a distancia (teletrabajo) en el horario establecido o en algunos casos se ha reducido la jornada de trabajo e incluso se han implementado los sistemas de turnos de trabajo. Solo se exime de prestar el servicio a las personas que tengan sesenta años, mujeres embarazadas o en periodo de lactancia, menores de cinco años, personas con discapacidad, personas con enfermedades crónicas no transmisibles, como por ejemplo, hipertensión arterial, pulmonar, insuficiencia renal, lupus, cáncer, diabetes mellitus, obesidad, insuficiencia hepática o metabólica, enfermedad cardiaca, o con algún padecimiento o tratamiento farmacológico que les genere supresión del sistema inmunológico conforme al Acuerdo por el que se estable- 
cen medidas preventivas que se deberán implementar para la mitigación y control de riesgos para la salud que implica la enfermedad por el virus SARS-CoV2 (COVID-19), publicado en el DOF de 24 de marzo de 2020.

Cabe mencionar que el acuerdo del 31 de marzo de 2020 se modificó por el Acuerdo de la Secretaría de Salud publicado en el DOF, el 21 de abril de 2020, que extendió el plazo de la vigencia original (30 de marzo al 30 de abril de 2020) hasta el 30 de mayo de 2020. Asimismo, la Secretaría de Salud emitió el Acuerdo por el que se establece una estrategia para la reapertura de las actividades sociales, educativas y económicas, así como un sistema de semáforo por regiones para evaluar semanalmente el riesgo epidemiológico relacionado con la reapertura de actividades en cada entidad federativa, así como el establecimiento de acciones extraordinarias. Este último acuerdo, publicado en el DOF el 14 de mayo de 2020, contiene un anexo que instituyó el semáforo por regiones y las actividades que podrían llevarse a cabo a partir del $1^{\circ}$ de junio de 2020.

Este conjunto de acuerdos y medidas extraordinarias establecidos para todo el territorio nacional propiciaron la abrupta afectación de las actividades económicas, industriales y de servicios como nunca en la Historia de México. La afectación de una suspensión casi total de la actividad económica privada devino en una crisis laboral de gran magnitud que se expresa en la pérdida de fuentes de trabajo tanto formales como aquellas pertenecientes al trabajo informal.

La Encuesta Nacional de Ocupación y Empleo del primer trimestre de 2020 reveló que hasta doce millones de personas, económicamente activas, habían suspendido labores sin goce de sueldo ni certeza de mantener su relación laboral. En el caso de la población ocupada que tiene la necesidad y disponibilidad de ofertar más tiempo de trabajo de lo que su ocupación actual demanda pasó de 5.1 millones de personas en marzo de 2020 a 11 millones en abril del mismo año, generando una tasa de subocupación de $25.4 \%$. De esta manera, en el mes de abril de 2020 tuvo lugar un incremento de 5.9 millones de personas subocupadas, esto es, 16.3 puntos porcentuales más que en marzo de 2020 (INEGI, 2020).

La Comisión Económica para América Latina y el Caribe (CEPAL, 2020) estima que el crecimiento de México durante este año será de alrededor del -6.6\%; como resultado de las cuarentenas implementadas, el menor envío de remesas, la reducción de precios de las materias primas, la baja en los ingresos del sector turístico, el incremento de la aversión al riesgo, las salidas de capitales y la volatilidad de los mercados financieros.

De acuerdo con la Organización Internacional del Trabajo (OIT, 2020), la crisis económica ocasionada por la pandemia de COVID-19 repercutirá adversamente en el mundo del trabajo en la cantidad de empleo, en el desempleo y el subempleo, pero sobre todo en los grupos más vulnerables. Procedamos al estudio de cada uno de estos elementos en el caso mexicano. 


\section{LA PANDEMIA DE COVID-19 Y EL EMPLEO EN MÉXICO}

A nivel mundial la pandemia por COVID-19 ha provocado el incremento sustancial del desempleo y subempleo. La OIT (2020) en el ámbito del desenpleo distingue tres posibles estimaciones:

a. Caso de baja incidencia, por el que el ritmo de aumento del PIB disminuye alrededor del 2\%; que daría lugar a 5,3 millones de desempleados más en todo el mundo, valor que podría oscilar entre 3,5 y 7 millones.

b. Caso de incidencia media, por el que el ritmo de aumento del PIB disminuye alrededor del 4\%; que daría lugar a 13 millones de desempleados más en todo el mundo (7,4 millones en los países de elevados ingresos), valor que podría oscilar entre 7,7 y 18,3 millones.

c. Caso de incidencia elevada, por el que el ritmo de aumento del PIB disminuye alrededor del 8\%; que daría lugar a 24,7 millones de desempleados más en todo el mundo, valor que podría oscilar entre 13 y 36 millones.

La OIT (2020) estima que ante el menor dinamismo de la economía en México durante el 2020, aproximadamente, 172,000 personas se ubicarán en el desempleo, circunstancia que se prolongará hasta el 2021. La tasa de desocupación del 3.4\% de la Población Económicamente Activa (PEA) en 2019 se incrementó a 3.7\% en el 2020 y aumentará a 4.1\% en el 2021. Ante tal escenario, el desempleo en los próximos dos años afectará a 2.3 millones de personas, es decir, 400,000 más que al cierre de diciembre de 2019. Tan solo se ha estimado que del 13 de marzo al 8 de abril de 2020 se perdieron 346 mil empleos que son el equivalente a los creados en 2019 (Secretaría del Trabajo, 2020). Las entidades federativas más afectadas son:

\section{Cuadro 1. Entidades federativas más afectadas por el desempleo}

\begin{tabular}{|c|c|}
\hline Entidad Federativa & Empleos perdidos \\
\hline Quintana Roo & I63 mil 847 \\
\hline Ciudad de México & 55 mil 591 \\
\hline Nuevo León & $23 \mathrm{mil} 465$ \\
\hline Jalisco & $21 \mathrm{mil} 535$ \\
\hline Estado de México & $16 \mathrm{mil} 036$ \\
\hline Tamaulipas & $12 \mathrm{mil} 652$ \\
\hline
\end{tabular}

Fuente: IMSS, 2020. 
El Instituto Nacional de Estadística y Geografía (INEGI) reportó que en abril de 2020 doce millones de personas se encontraban desempleadas, de las cuales, 8.1 millones pertenecían a micronegocios. La tasa de desocupación aumentó 1.7 puntos porcentuales al pasar de $2.9 \%$ en marzo de 2020 a 4.7\% en el mes de abril de este año. De acuerdo con las cifras anteriores, 2.1 millones de mexicanos carecían de empleo en abril de 2020 y 1.7 millones de mexicanos en el mes anterior (INEGI, 2020).

El $1^{\circ}$ de junio de 2020 se publicaron los resultados de la Encuesta Telefónica de Ocupación y Empleo (ETOE) que reportaron que la Tasa de Participación Económica en abril de 2020 fue del 47.5\% respecto a la población de 15 años y más, cifra que resultó inferior en 12.3 puntos porcentuales a la de marzo del mismo año. Esta disminución representó una variación a la baja de doce millones de personas económicamente activas por encontrarse en un estado de suspensión laboral temporal ocasionado por la cuarentena (INEGI, 2020).

Para el mes de mayo de 2020, el Instituto Mexicano del Seguro Social reportó la pérdida de 344,526 empleos formales que aunados a los 130,593 empleos perdidos en marzo y a los 555,247 empleos que se perdieron en abril sumaron más de un millón de empleos formales perdidos, cifra que es tres veces mayor a los 342,000 empleos formales que se crearon y registraron en 2019 en el IMSS; y es que el desempleo se agrava ante la falta de condiciones que permitan a las empresas generar empleos.

En marzo de 2020, la actividad industrial registró un decremento anual de $-4.9 \%$, derivado de la caída del $-7 \%$ en el sector de la construcción y $-6.4 \%$ en la industria manufacturera (Centro de Estudios de las Finanzas Públicas, 2020).

La Confederación de Cámaras Industriales de los Estados Unidos Mexicanos (CONCAMIN, 2020), cuyas empresas integrantes ocupan el 50\% de los veinte millones de trabajadores asegurados en el IMSS, advirtió que cinco de cada diez empresas cerrarán de manera definitiva, seis de cada diez han registrado un fuerte deterioro en sus ventas; $52 \%$ redujo su personal. En el sector comercio se estimaron pérdidas por cien mil millones de pesos, más de treinta mil restaurantes cerraron y para aquellos que retornen su actividad, las medidas sanitarias de la Nueva Normalidad, los obligarán a operar al 30\% de su capacidad. Incluso para el mes de mayo de 2020 se contabilizó el cierre de más de tres mil empresas de la construcción y el 90\% de la industria manufacturera.

La Cámara Nacional de Aerotransportes (CANAERO, 2020) reportó que el 90\% de la flota aérea estuvo en tierra por más de dos meses y calculó que las aerolíneas mexicanas perderán al menos treinta mil millones de pesos. Asimismo, de acuerdo con la Cámara Mexicana de la Industria de la Construcción, tres mil constructoras pequeñas y medianas dejarán de trabajar (CMIC, 2020); adicionalmente, INEGI (2020) señaló que la contracción económica del primer trimestre del 2020 y los primeros efectos negativos de la crisis de la pandemia de COVID-19 sobre la actividad productiva generaron una caída de 5.3\% en el Producto Interno Bruto (PIB) por persona.

En el reporte sobre Perspectivas para América Latina y el Caribe: La pandemia 
se intensifica, el Fondo Monetario Internacional (Werner, 2020) previó que el PIB real de México se redujo 10,5\% en 2020, y que para 2021 se recuperará el 3.3\% del PIB; la reducción del mismo resulta alarmante y supera las estimaciones realizadas durante los meses anteriores, las cuales oscilaban entre un $8.8 \%$ previsto en el escenario más pesimista elaborado por el Banco de México (2020) y 9.8\% considerado por Banorte (Financiero, 2020). Las cifras tampoco son favorables en cuanto a la recuperación estimada. Mientras que Banco de México (2020) estima que en 2021 tendrá lugar un crecimiento del 2.8\% del PIB, Banco Base estimó que esta recuperación sería de 1.5\%, además de advertir que para lograr una recuperación total y regresar al PIB reportado en 2018, le podría tomar a México hasta seis años (FORBES, 2020).

Un sector muy importante para el desarrollo económico del país son las micro, pequeñas y medianas empresas (MiPyMEs) que absorben una porción importante de la PEA, contribuyen significativamente al PIB y tienen un importante impacto en la generación de empleos. De acuerdo con la Comisión Nacional para la Protección y Defensa de los Usuarios de Servicios Financieros (CONDUSEF, 2020), las MiPyMEs generan 72\% del empleo y 52\% del PIB de nuestro país. Hasta antes de que se decretara la pandemia por COVID-19, en México, 4.1 millones de microempresas existentes aportaban el $41.8 \%$ del empleo total; contando con 174,800 pequeñas empresas que representan el $15.3 \%$ de empleabilidad; mientras que las medianas ascendían a 34,960 y generan $15.9 \%$ del empleo (INEGI, 2020).

La CEPAL (2020) dio a conocer en su Informe intitulado Sectores y Empresas frente a la pandemia de COVID-19: emergencia y reactivación, que aunque la crisis afecta a todas las empresas, el impacto será mucho mayor para las micro y pequeñas empresas por su peso en la estructura empresarial de la región y en la participación del empleo. En México se estimó el cierre de quinientas mil empresas formales con una pérdida del $11 \%$ de las MiPyMEs.

De acuerdo con un análisis de la Cámara de la Industria de la Transformación de Nuevo León (CAINTRA, 2020), las empresas más afectadas con la pandemia son las pequeñas con cerca del $50 \%$ a la baja de los registros patronales. Tan solo de marzo a mayo de este año, 827 patrones de Nuevo León dieron de baja su registro ante el IMSS. Las anteriores cifras representan una realidad nefasta para miles de familias mexicanas que se han quedado sin fuentes de sustento ante la pérdida del empleo ya que las MiPyMEs no cuentan con la estructura y capacidad económica para solventar los costos de la suspensión de labores.

\section{GRUPOS VULNERABLES EN MÉXICO ANTE LA PANDEMIA DE COVID-19}

Aproximadamente el 16\% de los hogares mexicanos perciben al menos el 50\% de sus ingresos de empleos prestados por grupos en situación de vulnerabilidad (Cejudo, 2020) como los trabajadores informales, migrantes, domésticos, niños y adolescentes con fuentes de ingreso poco estables. 
La pandemia de COVID-19 amenaza con agudizar las desigualdades de género, puesto que la responsabilidad del cuidado de los menores en el hogar, de familiares enfermos o de los adultos mayores recae de manera desproporcionada en las mujeres, debido a los estereotipos y roles de género continúan profundamente arraigados en muchas sociedades. En circunstancias de confinamiento o cuarentena para las familias, las mujeres pueden ser más vulnerables a sufrir violencia doméstica y los recursos que tienen a su alcance en esas circunstancias son limitados (CESCR, 2020).

La OIT (2020) resalta el impacto diferenciado que ha tenido la pandemia sobre las mujeres quienes prestan sus servicios en los sectores económicos más afectados por la crisis, como son el turismo, el comercio, la industria manufacturera y el trabajo informal. A nivel mundial, de los casi 510 millones de mujeres empleadas, el $40 \%$, trabaja en los cuatro sectores más afectados, frente a $36.6 \%$ de hombres. Las mujeres también predominan en los sectores del trabajo doméstico, la asistencia sanitaria y los servicios sociales, en donde corren mayores riesgos de perder sus ingresos y de infectarse.

El INEGI (2020) registró una disminución en el número de mujeres ocupadas en las actividades económicas al pasar de 22 millones 32 mil 255 en el último trimestre de 2019 a 21 millones 868 mil 95 en los primeros tres meses de 2020. La mayor disminución entre las mujeres fue en el grupo de 20 a 29 años y de 40 a 49 años. En México se estima que existen 2.2 millones de trabajadores domésticos, de los cuales el $94.8 \%$ son mujeres (OIT, 2020).

El 98.3\% de los trabajadores domésticos carece de servicios de salud, el 99.2\% no tiene un contrato de trabajo escrito y el $71.3 \%$ no recibe ninguna prestación laboral adicional. El 50.7\% de los hogares a los que pertenecen las trabajadoras domésticas son pobres en forma moderada o extrema, solo el 10.6\% está fuera de la línea de pobreza y vulnerabilidad. (OIT, 2020). En México 73 de cada cien mujeres de quince años o más que forma parte de la PEA tiene al menos un hijo nacido vivo. De las mujeres de quince años que son madres el $26.5 \%$ trabajan por cuenta propia. La posición en el trabajo de las mujeres de quince años y más ocupadas que son madres (14.8 millones), muestra que apenas $3.1 \%$ son empleadoras, $5.8 \%$ son trabajadoras sin pago, $26.5 \%$ trabajan por cuenta propia y el $64.6 \%$ se concentra en trabajadoras subordinadas remuneradas (INEGI, 2019).

A pesar de la reforma al artículo 12 de la Ley del Seguro Social para incluir a los trabajadores domésticos como sujetos de aseguramiento obligatorio, pocos se encuentran inscritos en el IMSS y ante la imposibilidad de laborar a distancia, además de los ajustes presupuestales de las familias que las emplean, son especialmente vulnerables ante la ola de "despidos suaves".

En el caso de los jóvenes, ${ }^{3}$ de los 178 millones de trabajadores de todo el mundo,

\footnotetext{
${ }^{2}$ Los despidos suaves consisten en pedirle al trabajador que se quede en su casa por seguridad, pero sin goce de sueldo.

${ }^{3}$ El concepto de juventud es un término que, por un lado, permite identificar el periodo de vida de una persona que se ubica entre la infancia y la adultez, que de acuerdo con la Ley del Instituto Mexicano de la Juventud (Imjuve), es entre los 12 a los 29 años.
} 
cuatro de cada diez laboraban en los sectores más afectados al surgir la crisis. Cerca del 77\% de jóvenes trabajadores en todo el mundo (328 millones) tenían un empleo en el sector informal (OIT, 2020). De acuerdo con la asociación civil, Alianza Jóvenes con Trabajo Digno (2020), hay un aumento del $41 \%$ de jóvenes desempleados, los jóvenes varones perdieron siete de cada diez empleos; mientras que las mujeres perdieron tres. Los estados de la República con las mayores pérdidas de empleo juvenil, de entre 15 y 29 años, son Quintana Roo, con 49 mil 584 puestos; Nuevo León, 30 mil 689; Jalisco, 25 mil 970; Estado de México, 21 mil 173, y Querétaro, 15 mil 174. En la Ciudad de México se perdieron 65 mil 876 plazas. Lo anterior representa el $55 \%$ de la pérdida de empleo en los jóvenes (AM, 2020).

Esta pérdida de empleos juveniles obedece a varios factores, entre los que destaca el hecho de que la mayoría de ellos, tienen poco tiempo de laborar en el centro de trabajo, perciben salarios bajos, por lo que su liquidación no menoscaba el patrimonio del empleador (AM, 2020). Los resultados de la Encuesta Nacional de Ocupación y Empleo (INEGI, 2020), revelaron que seis de cada diez de los jóvenes trabajadores en el país tienen cuando mucho tres años de antigüedad laboral y el 65\% no gana más de dos salarios mínimos, es decir, 7 mil 393 pesos en el mejor de los casos.

Previo al surgimiento de la crisis por la pandemia de COVID-19, existían casi 68 millones de jóvenes sin empleo y más de 267 millones de jóvenes carecían de empleo y no participaban en ningún programa educativo o de formación (jóvenes nini). En contraste con el desempleo al que se enfrentan los jóvenes, se pronostica un incremento del trabajo infantil. Se advierte que los derechos fundamentales de niñas, niños y adolescentes corren grave riesgo de transitar a una situación de alta vulnerabilidad, como consecuencia de la pandemia, pues en tiempos de crisis, el trabajo infantil ${ }^{4}$ hace posible la supervivencia para muchas familias (Organización de las Naciones Unidas, 2020).

Se estima que en México el trabajo infantil aumentará en un 5.5\%, esto es, 177,000 niñas, niños y adolescentes se sumarán con los 3.2 millones que se ven forzados a emplearse en actividades no permitidas por su edad o en el trabajo doméstico intensivo (Consejo Nacional de Evaluación de la Política de Desarrollo Social, 2020). La OIT y la Organización de las Naciones Unidas (2020), para contrarrestar la amenaza del aumento del trabajo infantil y evitar que los niños sean las víctimas ocultas de la actual pandemia, proponen las siguientes medidas: implementar la protección social integral, un acceso más fácil al crédito para los hogares pobres, la promoción del trabajo decente para adultos, medidas para que los niños vuelvan a la escuela, la eliminación de cuotas escolares, dotar de más recursos para llevar a cabo las inspecciones laborales y cumplimiento de la ley para evitar y, en su caso sancionar el trabajo infantil.

Otro de los sectores vulnerables debido a las medidas de confinamiento es el de los trabajadores informales dado que, el INEGI atribuye el carácter de empleado del

\footnotetext{
${ }^{4}$ De acuerdo con la CEPAL, el término trabajo infantil se define como todo trabajo que priva a los niños, niñas y adolescentes de su niñez, potencial y dignidad, siendo perjudicial para su desarrollo físico y psicológico.
} 
sector informal, a quienes laboran en unidades económicas no agropecuarias, no constituidas como empresas y que no cumplen con registros básicos de proveedores de bienes y servicios; sin embargo, a partir de la XVII Conferencia Internacional de Estadísticos del Trabajo (2003) como parte de este sector se consideran a aquellos que a pesar de estar fuera de la informalidad, presentan condiciones laborales consideradas informales, tales como el autoempleo en la agricultura, la no remuneración o la carencia de seguridad social.

Si bien el 55\% de la PEA de México trabaja en la informalidad como resultado de las acciones realizadas para contrarrestar la pandemia de COVID-19, existe un decremento en la tasa de informalidad laboral ${ }^{5}$ al ubicarse en $47.7 \%$ de la población ocupada en abril de 2020, (-)8.0 puntos porcentuales inferior a la del mes previo y (-)8.7 con relación a la de abril de 2019, lo que provoca la perdida de empleo informal en 10.4 millones (INEGI, 2020).

Ante la suspensión de las actividades laborales los trabajadores informales quedaron desprotegidos porque no hay quien les pague sus ingresos y no tienen ahorros para enfrentar la crisis económica, además de que, al carecer de seguridad social, no pueden ser beneficiarios de los seguros de desempleo y enfermedades.

El último grupo vulnerable son los trabajadores migrantes pues recordemos que la historia de la humanidad está hecha de migración y uno de los principales países con un importante flujo de trabajadores migrantes es México. Los últimos resultados de la Encuesta Nacional de la Dinámica Demográfica (ENADID) evidenciaron que el principal destino de los migrantes mexicanos continúa siendo los Estados Unidos de América (EUA) con el 84.8\%, de ellos, el 27\% carece de documentos, el 15.8\% cuenta con visa de turista y el 10.2\% tiene permiso para residir (INEGI, 2019).

El Anuario de Migración y Remesas señala que en los EUA existen por lo menos 38.5 millones de mexicanos, de los cuales 12.3 millones son migrantes, 13.5 millones hijos de migrantes mexicanos y 12.7 millones más con ascendencia mexicana (Secretaría de Gobernación 2019). Los mexicanos aproximadamente representan el $64.6 \%$ del total de la población hispana y el 10.8\% de la población total de los EUA (Instituto de los Mexicanos en el Exterior, 2018).

Los migrantes mexicanos representan una fuerza laboral relevante en los países de destino. En 2018 en EUA, 8.1 millones de migrantes mexicanos formaron parte de la PEA de ese país (Secretaría de Gobernación 2019). Las principales actividades económicas en las que destaca la presencia de nuestros connacionales son la construcción, la manufactura, actividades profesionales y administrativas, comercio y las agrícolas, empero el trabajo de los migrantes mexicanos no sólo es clave para la prosperidad y el crecimiento económico de EUA, sino también para nuestro país, pues las remesas constituyen un importante rubro de la economía nacional al representar el 2.7\% del PIB (Secretaría de Gobernación 2019).

\footnotetext{
${ }^{5}$ De acuerdo con el INEGI, la tasa de informalidad laboral comprende a los ocupados que son laboralmente vulnerables por la naturaleza de la unidad económica para la que prestan sus servicios como aquellos cuyo vínculo o dependencia laboral no es reconocido por su fuente de trabajo.
} 
En 2018 el monto de las remesas fue de 36 mil 45 millones de dólares y el mes de marzo de 2020 las remesas alcanzaron los 4 mil millones de dólares (Banco de México, 2020). Pese a lo anterior, la pandemia de COVID-19 comenzó a mostrar estragos en la economía de los migrantes mexicanos en EUA. El desempleo en diferentes sectores productivos, resultado de las medidas de confinamiento y la recesión económica en la que entró EUA desde el mes de febrero de 2020, afecta a nuestros connacionales que se encuentran viviendo en ese país sin ningún tipo de prestación social y defensa jurídica ante los despidos injustificados. Se estima que en abril se registró la caída más pronunciada de empleos en EUA desde la Gran Depresión en 1929, con una pérdida de por lo menos 20.5 millones de empleos. En mayo la tasa nacional de desempleo alcanzó el 14.7\%, mientras que en la población latina aumentó al 13.6\%. Bajo este panorama, el desempleo, la deportación, la violencia, la discriminación, acceso nulo o limitado a la cobertura de seguridad social, condiciones de vida indecentes y la explotación, no son los únicos problemas de nuestros connacionales en Estados Unidos, ahora también lo es, la COVID-19.

\section{MEDIDAS PARA ABATIR LOS EFECTOS DE LA PANDEMIA DE COVID-19 EN EL ÁMBITO LABORAL}

Los organismos regionales y de derechos humanos han formulado una serie de recomendaciones para contrarrestar las adversidades derivadas de la pandemia, sin embargo, en este apartado, solo se hace referencia a las relacionadas con el ámbito laboral.

Para la CEPAL (2020) la pandemia tendrá efectos graves a corto, mediano y largo plazo. En el primer tipo de efectos se encuentran un mayor desempleo y menores salarios e ingresos; en tanto que los efectos de mediano y largo plazos producirán la quiebra de empresas, disminución de la inversión privada, menor crecimiento económico e integración en cadenas de valor, así como deterioro de las capacidades productivas y del capital humano. Ante este escenario a partir de la Agenda Regional de Desarrollo Social Inclusivo aprobada en 2019, el fortalecimiento del Estado de Bienestar y la provisión universal de protección social, la CEPAL (2020) propone el establecimiento de una garantía universal de ingresos, cuyos principales destinatarios sean los trabajadores informales y precarios como paliativo para contrarrestar los efectos de corto plazo y estar en la posibilidad de atender las necesidades más agudas de la emergencia.

A lo anterior, el organismo regional adiciona la articulación de acciones orientadas a garantizar el ejercicio de los derechos de las personas y a consolidar sistemas universales de protección social, basados en un enfoque de derechos sensibles a las diferencias, asi como a desarrollar estrategias de inclusión laboral en el período de la recuperación. Estos sistemas permitirán identificar y responder a los impactos de la crisis en el empleo y las condiciones de vida de las personas, a atender la situación diferenciada que enfrentan diversas poblaciones con la atención oportuna 
a los trabajadores informales, los grupos etarios más vulnerables, los habitantes de áreas rurales y remotas, los pueblos indígenas, las poblaciones de afrodescendientes, así como las personas con discapacidad y los migrantes (CEPAL, 2020).

Por su parte, la OIT (2020) como organismo especializado en temas del derecho laboral y de seguridad social, propone medidas económicas, políticas, financieras, fiscales y sociales para abatir los efectos negativos de la pandemia, principalmente en el ámbito social, dichas medidas destinadas a la protección de los trabajadores y empleadores.

Las acciones que propone la OIT en el terreno laboral son las siguientes:

a. La implantación de medidas de protección en el lugar de trabajo, dentro de las cuales se encuentran las siguientes: el distanciamiento social, el suministro de equipos de protección (especialmente para los trabajadores sanitarios y afines, voluntarios y otras personas que estén en contacto permanente con la población), los procedimientos de higiene y los métodos de organización del trabajo (con apoyo de campañas de información y aumento de la concienciación).

b. La ampliación del derecho a bajas remuneradas o subsidios por enfermedad, para ocuparse del cuidado de los hijos o atender a otras personas, en el marco de programas de financiación conjunta, con la finalidad de garantizar la estabilidad de los ingresos de personas enfermas, en situación de cuarentena o responsables del cuidado de menores, personas de edad avanzada u otros miembros de su familia.

c. Establecer disposiciones referentes a la conservación del empleo, concertar acuerdos sobre la reducción de la jornada laboral y de las prestaciones parciales por desempleo. Conceder subvenciones salariales, reducción temporal de las retenciones fiscales en nómina, exención del pago de las cotizaciones a la seguridad social, entre otras medidas conexas como formas de apoyo a las empresas por un período de tiempo determinado.

d. El fomento de acuerdos laborales flexibles y adecuados sobre el teletrabajo.

e. Propiciar el diálogo social entre patrones, trabajadores y sus representantes.

En el ámbito financiero y fiscal con repercusiones en la esfera laboral, la OIT (2020) propone la implementación de medidas de ayuda financiera o de reducción fiscal y de estabilización de ingresos por un período de tiempo determinado, con la finalidad de garantizar la continuidad de la actividad empresarial, en particular respecto de las PYMES y los trabajadores por cuenta propia a través del otorgamiento de subsidios, programas de mediación para facilitar la concesión o la refinanciación de créditos con el fin de soslayar las restricciones de liquidez. La instauración de políticas monetarias flexibles, reducción de tipos de interés, flexibilización de los coeficientes de reserva y disposiciones específicas en materia de liquidez.

A nivel político es necesario implementar medidas a gran escala de forma 
oportuna y coordinada para fomentar el empleo y los ingresos, además de promover la economía y la demanda de mano de obra. Estos apoyos permitirían paliar los efectos de las pérdidas de empleo e ingresos de las empresas y de los trabajadores a corto plazo, así como soslayar los efectos adversos en la oferta (incluida la pérdida de capacidad productiva de los trabajadores) y en la demanda (drástica reducción del consumo de los trabajadores y sus familias), para que no se produzca una recesión económica prolongada. Es primordial llevar a cabo un seguimiento meticuloso de los efectos directos e indirectos de cada intervención, a fin de velar por la pertinencia de las medidas de respuesta en el plano normativo (OIT, 2020).

En el ámbito económico se propone el fomento de la actividad económica y de la demanda de mano de obra mediante políticas económicas y de empleo que contribuyan a estabilizar la actividad económica, por medio de políticas fiscales eficaces, medidas de protección social, transferencias específicas y factores de estabilización automática sobre la base de prestaciones por desempleo, inversión pública y reducciones fiscales para personas de bajos ingresos y las PYMES (OIT, 2020).

Por último, en cuanto a las medidas propuestas destacan las realizadas por los organismos de derechos humanos. Con el apoyo de las Relatorías Especiales sobre los Derechos Económicos, Sociales, Culturales y Ambientales y sobre Libertad de Expresión, la Comisión Interamericana de Derechos Humanos (CIDH, 2020) adoptó el 10 de abril de 2020 la Resolución 1/2020, bajo la convicción de que las medidas adoptadas por los Estados en la atención y contención de la pandemia deben tener como centro el pleno respeto de los derechos humanos.

La CIDH (2020) considera que, si bien existen impactos sobre todos los derechos humanos frente a los diversos contextos ocasionados por la pandemia, especialmente con relación al derecho a la vida ya que, la salud e integridad personal se ven seriamente afectados, el derecho al trabajo, a la seguridad social, a la educación, a la alimentación, al agua y a la vivienda, entre otros derechos económicos, sociales, culturales y ambientales (DESCA).

Las recomendaciones de la CIDH (2020) para combatir los efectos de la pandemia en el ámbito laboral son la protección de los derechos humanos, y particularmente los DESCA, de las personas trabajadoras en mayor situación de riesgo por la pandemia y sus consecuencias. Considera necesaria la adopción de las medidas que velen por asegurar los ingresos económicos y medios de subsistencia de todas las personas trabajadoras de manera que tengan igualdad de condiciones para cumplir las medidas de contención y protección durante la pandemia, así como condiciones de acceso a la alimentación y otros derechos esenciales. Las personas que hayan de proseguir realizando sus actividades laborales deben ser protegidas de los riesgos de contagio del virus y, en general, se debe dar adecuada protección a los trabajos, salarios, la libertad sindical y negociación colectiva, pensiones y demás derechos sociales interrelacionados con el ámbito laboral y sindical.

Toda vez que las empresas tienen un rol clave que desempeñar en estos contextos y su conducta debe guiarse por los principios y reglas de los derechos huma- 
nos aplicables, la CIDH (2020) considera que es necesario exigir y vigilar que las empresas respeten los derechos humanos, adopten procesos de debida diligencia en materia de derechos humanos y rindan cuentas ante posibles abusos e impactos negativos sobre los derechos humanos, particularmente por los efectos que los contextos de pandemia y crisis sanitarias infecciosas suelen generar sobre los DESCA de las poblaciones y grupos en mayor situación de vulnerabilidad y, en general, sobre las personas que trabajan, las personas con condiciones médicas sensibles y las comunidades locales.

Por su parte, la Declaración sobre la pandemia de enfermedad por coronavirus (COVID-19) y los derechos económicos, sociales y culturales aprobados el 6 de abril de 2020 por el Comité de Derechos Económicos, Sociales y Culturales (CESCR, 2020) en el ámbito del derecho al trabajo propone la práctica de programas específicos para proteger los empleos, los salarios y las prestaciones de todos los trabajadores, incluidos los trabajadores migrantes sin papeles. Para proteger los empleos, las pensiones y otras prestaciones sociales de los trabajadores durante la pandemia, así como para mitigar los efectos económicos de esta, los Estados parte deben adoptar medidas inmediatas como subvenciones salariales, desgravaciones fiscales y la implantación de programas complementarios en el ámbito de la seguridad social y la protección de los ingresos (CESCR, 2020).

Para el CESCR (2020), todos los trabajadores deben estar protegidos de los riesgos de contagio en el trabajo, y los Estados parte deben adoptar medidas reglamentarias apropiadas para garantizar que los patrones reduzcan al mínimo los riesgos de contagio con arreglo a las mejores prácticas en materia de normas de salud pública. Mientras no se adopten esas medidas, no se puede obligar a los trabajadores a trabajar y se les debe proteger de la aplicación de sanciones disciplinarias o de otra índole por negarse a prestar sus servicios sin la debida y adecuada protección.

\section{MEDIDAS ADOPTADAS POR EL ESTADO MEXICANO PARA ABATIR LOS EFECTOS DE LA PANDEMIA DE COVID-19 EN EL ÁMBITO LABORAL}

De acuerdo con los datos brindados por el Fondo Monetario Internacional México ha destinado el $1.2 \%$ del PIB en apoyos para enfrentar la contingencia, divididos en $0.7 \%$ en recursos adicionales al sector salud y otros sectores, así como el $0.5 \%$ en medidas de crédito y liquidez. Por tal motivo, el FMI recomienda un incremento en el gasto público para proteger las vidas y los ingresos de las familias mexicanas, además de trazar un plan creíble de reforma fiscal a mediano plazo que amplíe el margen para la aplicación de políticas a corto plazo y que permita cerrar las brechas fiscales (Werner, 2020).

Algunos de los apoyos económicos implementados son: "Querétaro Fuerte" consiste en una bolsa de 240 millones de pesos destinada a la población que perdió su empleo o su fuente de ingresos (Estrella, 2020), en Yucatán el programa “Microyuc 
Emprendedores" para implementar el plan estatal para impulsar la economía, los empleos y la salud que tiene como beneficiarios a los sectores empresarial, emprendedor y artesanal, agropecuario, turístico, hotelero, restaurantero y cultural, pesquero, vivienda, personas con desempleo, subempleo o autoempleo que haya sido afectadas en sus ingresos y personas en situación de vulnerabilidad (Diario Oficial del Gobierno del Estado de Yucatán, 2020); en los estados de Puebla y San Luis Potosí destacan los apoyos financieros y fiscales otorgados a las PYMES, la Ciudad de México implantó el seguro de desempleo para el sector formal, apoyos económicos para los trabajadores informales y un programa especial para las trabajadoras sexuales, las familias de escasos recursos, las microempresas y emprendedores (Gobierno Ciudad de México, 2020).

Por su parte, CAINTRA (2020) inició una serie de apoyos mediante el otorgamiento de los llamados créditos directos "a la palabra”, de treinta mil pesos a empresas de hasta diez trabajadores. Alrededor de 150 empresas han recibido este apoyo, a la vez decidió aportar de su fondo patrimonial veinte millones de pesos para que sean utilizados como garantía y potenciar el crédito por parte de Nacional Financiera (NAFIN) hacia las empresas socias de CAINTRA con una antigüedad de 5 años o más de afiliación. Las condiciones de crédito son: a. El monto disponible es de hasta un millón de pesos o su equivalente en dólares y el destino es a capital de trabajo o inversión que mejore la capacidad productiva; $b$. El plazo es a 36 meses con un periodo de gracia de nueve meses para cubrir el crédito, y c. La tasa de interés es de 13.9\% anual.

Asimismo, destaca el Apoyo para el Bienestar de Pescadores y Acuicultores por un monto de $\$ 7,200$ que tiene como objetivo fomentar el desarrollo productivo de las comunidades pesqueras en estado de vulnerabilidad e impactar de manera directa en las regiones costeras del país para incrementar el empleo, los ingresos y el bienestar de los productores (Comisión Nacional de Acuacultura y Pesca, 2020).

Otra de las medidas que se propone para contrarestar las adversidades de la pandemia es el ingreso ciudadano universal también denominado ingreso básico universal o renta básica universal que es un pago en efectivo que se entrega de manera periódica a todos los ciudadanos con independencia de otras fuentes de ingreso y sin necesidad de cumplir con requerimientos o condiciones para recibirlo o ejercerlo (Gutiérrez Lara, 2018). Este ingreso se basa en tres principios básicos: universalidad, asignación y uso incondicional del recurso (Scott, 2017, p. 41), cuyo monto, características y sus posibles beneficiarios han sido desarrollados por quienes proponen la implantación de este ingreso, como a continuación se detalla en el cuadro siguiente: 


\section{Cuadro 2. Iniciativas de reforma constitucional en materia de ingreso básico universal}

\begin{tabular}{|c|c|}
\hline Promovente & Propuestas \\
\hline $\begin{array}{l}\text { Senadora Kenia } \\
\text { López Rabadán } \\
1^{\circ} \text { de abril de } 2020\end{array}$ & $\begin{array}{l}\text { Iniciativa con Proyecto de Decreto por el que se adiciona un párrafo al artículo } 4^{\circ} \text { de } \\
\text { la Constitución Política de los Estados Unidos Mexicanos, en materia de apoyos } \\
\text { económicos durante epidemias graves a personas que tengan un ingreso inferior a } \\
\text { cinco salarios mínimo o no cuenten con un ingreso formal. }\end{array}$ \\
\hline $\begin{array}{l}\text { Senador Noé } \\
\text { Fernando } \\
\text { Castañón Ramírez } \\
3 \text { de abril de } 2020\end{array}$ & $\begin{array}{l}\text { Iniciativa con Proyecto de Decreto por el que se reforma y adiciona el artículo } 4^{\circ} \text { de } \\
\text { la Constitución Política de los Estados Unidos Mexicanos. Esta iniciativa propone el } \\
\text { establecimiento de un ingreso básico universal de emergencia sanitaria por un } \\
\text { periodo mínimo de un mes y un máximo de tres meses. }\end{array}$ \\
\hline $\begin{array}{l}\text { Diputada } \\
\text { Erika Vanessa } \\
\text { Del Castillo Ibarra } \\
14 \text { de abril de } 2020\end{array}$ & $\begin{array}{l}\text { Iniciativa con Proyecto de Decreto que reforma el párrafo cuarto del artículo } 4^{\circ} \text { y se } \\
\text { reforma la fracción XXIX-D del artículo } 73 \text {, de la Constitución Política de los Estados } \\
\text { Unidos Mexicanos, en materia de ingreso básico universal. (IBU). La iniciativa } \\
\text { propone que se instituya el derecho de toda persona a un IBU a partir de su } \\
\text { nacimiento. }\end{array}$ \\
\hline $\begin{array}{l}\text { Diputadas Lorena } \\
\text { Villavicencio } \\
\text { Ayala y Gabriela } \\
\text { Cuevas Barrón y } \\
\text { Diputado Porfirio } \\
\text { Muñoz Ledo } \\
3 \text { de junio de } 2020\end{array}$ & $\begin{array}{l}\text { Iniciativa con Proyecto de Decreto que adicionan; un párrafo al artículo } 4^{\circ} \text {, un } \\
\text { párrafo al artículo } 35 \text { y una fracción XXI al artículo 73, de la Constitución Política de } \\
\text { los Estados Unidos Mexicanos, en materia de ingreso básico ciudadano. La iniciativa } \\
\text { propone crear el ingreso básico ciudadano que garantice a las personas mayores de } \\
\text { dieciocho años recursos por encima del límite de la pobreza. }\end{array}$ \\
\hline $\begin{array}{l}\text { Senador José } \\
\text { Ramón Enríquez } \\
\text { Herrera } \\
3 \text { de junio de } 2020\end{array}$ & $\begin{array}{l}\text { Iniciativa con proyecto de decreto por el que se expide la Ley del Ingreso Mínimo } \\
\text { Vital para Situaciones Especiales; y se reforman la Ley General de Desarrollo Social y } \\
\text { la Ley del Sistema Nacional de Información Estadística y Geográfica. Esta iniciativa } \\
\text { propone la expedición de la Ley del Ingreso Mínimo Vital para Situaciones Especia- } \\
\text { les (LIMVSE), cuyas principales directrices serían: a. Reconocer que, de ocurrir } \\
\text { situaciones especiales, el Estado deberá garantizar el derecho a un ingreso mínimo } \\
\text { vital (IMV) a todas las personas que vean afectados sus ingresos económicos. De } \\
\text { acuerdo con la LIMVSE, la situación especial se define como aquella donde por } \\
\text { cualquier tipo de contingencia o suceso imprevisto se ve afectada gravemente la } \\
\text { economía nacional, la ocupación laboral y los ingresos o remuneraciones de las } \\
\text { personas; b. Las personas benefiviarias del IMV serían: las personas trabajadoras que } \\
\text { hayan perdido su empleo y las personas que vean mermados sus ingresos económi- } \\
\text { cos ante la imposibilidad de realizar sus actividades laborales como consecuencia de } \\
\text { una situación especial; c. El IMV será entregado durante tres meses a los beneficiari- } \\
\text { os y podrá ser renovado por dos meses adicionales en caso de que sea necesario para } \\
\text { casos específicos en donde sea observable que su situación económica no ha podido } \\
\text { mejorar; d. El valor del IMV será igual al monto mensual del salario mínimo, que en } \\
\text { el año } 2020 \text { es de \$123.22 al día, es decir, \$3,696.6 mensuales; e. El Consejo Nacional } \\
\text { de Evaluación de la Política de Desarrollo Social (CONEVAL) tendrá a su cargo la } \\
\text { evaluación permanente de esta política y podrá emitir recomendaciones sobre la } \\
\text { misma. La reforma a la Ley General de Desarrollo Social propone la implantación de } \\
\text { programas prioritarios y de interés público orientados a garantizar el acceso al IMV } \\
\text { y a través de la reforma a la Ley del Sistema Nacional de Información Estadística y } \\
\text { Geográfica se propone que el desarrollo del catálogo de grupos poblacionales y } \\
\text { ocupacionales que podrán ser acreedores del IMV sea de la competencia del INEGI. }\end{array}$ \\
\hline $\begin{array}{l}\text { Grupo Parlamentario } \\
\text { del PRD } \\
3 \text { de junio de } 2020\end{array}$ & $\begin{array}{l}\text { Iniciativa que adiciona un párrafo quinto, recorriéndose los subsiguientes, al } \\
\text { artículo } 4^{\circ} \text { de la Constitución Política de los Estados Unidos Mexicanos. La iniciativa } \\
\text { tiene por objeto establecer el derecho de todo individuo al ingreso mínimo vital. }\end{array}$ \\
\hline
\end{tabular}




\begin{tabular}{|c|c|}
\hline $\begin{array}{l}\text { Senadora } \\
\text { Claudia Ruiz } \\
\text { Massieu Salinas } \\
3 \text { de junio de } 2020\end{array}$ & $\begin{array}{l}\text { Iniciativa con proyecto de decreto por el que se adiciona el párrafo décimo cuarto al } \\
\text { artículo } 4 \text { de la Constitución Política de los Estados Unidos Mexicanos, en materia de } \\
\text { ingreso básico vital (IBV). La iniciativa propone que se garantice la entrega de un IBV } \\
\text { excepcional, extraordinario, universal, no condicionado, no contributivo, } \\
\text { distribuible, con perspectiva de género y temporal, cuando se presenten emergen- } \\
\text { cias económicas o de cualquier otra índole, decretadas por el Gobierno Federal. }\end{array}$ \\
\hline $\begin{array}{l}\text { Senador Damián } \\
\text { Zepeda Vidales } \\
10 \text { de junio de } 2020\end{array}$ & $\begin{array}{l}\text { Iniciativa con proyecto de decreto por el que se adiciona un párrafo último al } \\
\text { artículo } 4 \text { de la Constitución Política de los Estados Unidos Mexicanos, en materia de } \\
\text { ingreso básico universal para emergencias para las personas económicamente } \\
\text { activas, formales e informales, en caso de suspensión de las relaciones laborales o } \\
\text { para contrarrestar el impacto negativo económico derivado de una contingencia } \\
\text { sanitaria que declare la autoridad sanitaria competente y para aquellas personas } \\
\text { cuyas empresas lleven a cabo suspensión colectiva de las relaciones de trabajo. De } \\
\text { acuerdo con esta iniciativa el ingreso básico universal deberá ser suficiente para } \\
\text { cubrir la Línea de Bienestar establecida por el CONEVAL, esto es, } \$ 3,207 \text { pesos al mes. }\end{array}$ \\
\hline $\begin{array}{l}\text { Diputada } \\
\text { Laura Angélica } \\
\text { Rojas Hernández } \\
10 \text { de junio de } 2020 \\
\text { Se solicitó el retiro } \\
\text { de la iniciativa }\end{array}$ & $\begin{array}{l}\text { Iniciativa con proyecto de decreto por el que se reforma el artículo } 4^{\circ} \text { de la Consti- } \\
\text { tución Política de los Estados Unidos Mexicanos, en materia de ingreso mínimo vital } \\
\text { de emergencia (IMVE). Esta iniciativa tiene por objeto la incorporación del IMVE, } \\
\text { consistente en un apoyo económico no contributivo, por un periodo mínimo de } \\
\text { treinta días y máximo de noventa días, destinado a todos los que desempeñen } \\
\text { actividades laborales, formales e informales, y en general, a todas las personas a las } \\
\text { que afecte de manera directa o indirecta en sus ingresos la suspensión de actividades } \\
\text { derivada de una emergencia sanitaria. }\end{array}$ \\
\hline $\begin{array}{l}\text { Diputado } \\
\text { Fernando Luis } \\
\text { Manzanilla Prieto } \\
8 \text { de julio de } 2020\end{array}$ & $\begin{array}{l}\text { Iniciativa con proyecto de decreto por el que se adiciona un último párrafo con tres } \\
\text { bases al artículo } 4^{\circ} \text { de la Constitución Política de los Estados Unidos Mexicanos. La } \\
\text { iniciativa propone el establecimiento de la prestación económica denominada } \\
\text { Ingreso Mínimo de Emergencia (IME) que podrá cubrirse hasta por un período } \\
\text { máximo de } 120 \text { días naturales a los siguientes destinatarios: a. Las personas que } \\
\text { durante el periodo que dure la suspensión de actividades hubieran perdido su } \\
\text { empleo o les resultara imposible la prestación de servicios profesionales, el trabajo } \\
\text { por cuenta propia y el no asalariado, la producción de bienes de manufactura } \\
\text { artesanal, así como el comercio en el espacio público, quienes tendrán derecho a un } \\
\text { IME por un límite equivalente a la Línea de Bienestar publicada por el CONEVAL. b. } \\
\text { Las personas que, encontrándose en el supuesto de la base anterior, sean además } \\
\text { beneficiarios de programas sociales del gobierno federal, recibirán una aportación } \\
\text { suficiente hasta coincidir con la Línea de Bienestar publicada por el CONEVAL. }\end{array}$ \\
\hline $\begin{array}{l}\text { Senador Miguel } \\
\text { Ángel Mancera } \\
\text { Espinosa } \\
20 \text { de julio de } 2020\end{array}$ & $\begin{array}{l}\text { Iniciativa con proyecto de decreto por el que se adiciona un último párrafo al } \\
\text { artículo 4o. de la Constitución Política de los Estados Unidos Mexicanos. El objeto de } \\
\text { la iniciativa es establecer en el texto constitucional el derecho de todas las personas } \\
\text { a un mínimo vital. }\end{array}$ \\
\hline $\begin{array}{l}\text { Diputado Isaías } \\
\text { González Cuevas } \\
20 \text { de julio de } 2020\end{array}$ & $\begin{array}{l}\text { Iniciativa con proyecto de decreto por el que se adiciona un último párrafo al } \\
\text { artículo } 4^{\circ} \text { de la Constitución Política de los Estados Unidos Mexicanos, en materia } \\
\text { de renta básica universal. La iniciativa propone establecer el derecho una renta } \\
\text { básica universal en la Constitución mexicana, cuyo monto mensual no podrá ser } \\
\text { inferior al de un salario mínimo vigente en el país. }\end{array}$ \\
\hline
\end{tabular}

Fuente: Gacetas de la Comisión Permanente. 
Otros beneficios que se proponen son los siguientes:

\section{Cuadro 3. Otros beneficios con repercusiones en el ámbito laboral}

\begin{tabular}{|c|c|}
\hline Promovente & Propuestas \\
\hline $\begin{array}{c}\text { Senadora } \\
\text { Geovanna del } \\
\text { Carmen Bañuelos } \\
\text { de la Torre } \\
27 \text { de mayo de } \\
2020\end{array}$ & $\begin{array}{l}\text { Iniciativa, con proyecto de decreto que reforman los artículos } 4^{\circ}, 73 \text { y } 123 \text { de la Consti- } \\
\text { tución Política de los Estados Unidos Mexicanos por medio de la cual se crea el } \\
\text { seguro de desempleo para trabajadores formales e informales. La iniciativa tiene por } \\
\text { objeto: a. Establecer el derecho de toda persona a un ingreso básico a modo de seguro } \\
\text { de desempleo, el cual será suficiente para garantizar el goce y el ejercicio de sus } \\
\text { derechos humanos; b. El monto del subsidio no podrá ser inferior a tres salarios } \\
\text { mínimos, ni podrá tener una duración menor a tres meses; c. Precisar que el Estado } \\
\text { mexicano tiene la obligación de garantizar el ejercicio de este derecho en un plazo no } \\
\text { mayor a cinco días hábiles; d. Facultar al Congreso para expedir leyes en materia de } \\
\text { seguro universal de desempleo; e. Las personas que no se encuentren debidamente } \\
\text { contratadas o pertenezcan al sector informal de la economía podrán acceder al } \\
\text { ingreso básico. }\end{array}$ \\
\hline $\begin{array}{c}\text { Partido del } \\
\text { Trabajo } \\
20 \text { de julio de } \\
2020\end{array}$ & $\begin{array}{l}\text { Iniciativa con proyecto de decreto por el que se expide la Ley Emergente para la } \\
\text { protección y recuperación del trabajo. Como su nombre lo indica esta iniciativa } \\
\text { propone la expedición de la Ley Emergente para la Protección y Recuperación del } \\
\text { Trabajo (LEPRT), cuyos beneficiarios serán: a. Los trabajadores que hasta el } 30 \text { de } \\
\text { marzo de } 2020 \text { estaban inscritos y cotizaban en el IMSS y que perdieron su trabajo } \\
\text { dentro de los } 92 \text { días naturales posteriores a la declaración de emergencia sanitaria } \\
\text { por el virus SARS-CoV2; b. Los contribuyentes que antes de la entrada en vigor de la } \\
\text { Ley propuesta tributaban el Impuesto Sobre la Renta en los términos establecidos en } \\
\text { el Título IV, Capítulo II, Sección II, de la Ley del Impuesto Sobre la Renta y estaban al } \\
\text { corriente en sus contribuciones; c. Los sujetos señalados en el artículo Tercero del } \\
\text { Decreto publicado el } 8 \text { de abril de } 2014 \text { en el DOF, por el que se otorgan estímulos } \\
\text { para promover la incorporación a la seguridad social, que se encuentren al corriente } \\
\text { en sus contribuciones; y d. Los patrones que registren un puesto de nueva creación } \\
\text { en los términos de la LEPRT y durante la vigencia de esta. }\end{array}$ \\
\hline $\begin{array}{l}\text { Senador Miguel } \\
\text { Ángel Mancera } \\
\text { Espinosa } \\
20 \text { de julio de } \\
2020\end{array}$ & $\begin{array}{l}\text { Iniciativa con proyecto de decreto por el que se reforma el artículo } 123 \text { de la Consti- } \\
\text { tución Política de los Estados Unidos Mexicanos. La iniciativa tiene por objeto } \\
\text { incorporar la figura del teletrabajo en el artículo } 123 \text { de la Constitución Política de los } \\
\text { Estados Unidos Mexicanos, para ello, en primer lugar se propone facultar al Congre- } \\
\text { so de la Unión para expedir la regulación relativa al teletrabajo, ademád de la } \\
\text { incorporación de la fracción XXXII al apartado A, y la fracción XV al apartado B del } \\
\text { artículo } 123 \text { constitucional con la finalidad de que las actividades laborales que se } \\
\text { circunscriben a las relaciones obrero-patronales, así como las que se desarrollan } \\
\text { entre los Poderes de la Unión y sus personas trabajadoras, puedan desarrollarse a } \\
\text { través del teletrabajo. }\end{array}$ \\
\hline COPARMEX & $\begin{array}{l}\text { Propone el otorgamiento del salario solidario que deberá ser cubierto por las empre- } \\
\text { sas y el Gobierno Federal a los trabajadores que perciben un salario bajo. }\end{array}$ \\
\hline
\end{tabular}

Fuente: Gacetas de la Comisión Permanente.

En sede jurisdiccional se propone la implementación del mínimo vital. En México, el mínimo vital es el derecho humano a gozar de prestaciones e ingresos mínimos que aseguren a todo individuo una subsistencia y un nivel de vida dignos, así como la satisfacción de las necesidades básicas. Este derecho deriva del principio de 
dignidad humana, en concordancia con los derechos fundamentales a la vida, a la integridad personal y a la igualdad, en la modalidad de decisiones de protección especial a personas en situación de necesidad manifiesta. (Tesis 1a. XCVII/2007, mayo de 2007).

Conforme al Derecho constitucional mexicano y al Derecho Internacional de los Derechos Humanos, el derecho al mínimo vital tiene por objeto salvaguardar los derechos fundamentales de las personas para evitar que sean reducidas en su valor intrínseco como seres humanos, por no contar con las condiciones mínimas que les permitan llevar y desarrollar una existencia digna, un plan de vida autónomo a fin de facilitar que los gobernados participen activamente en la vida democrática (Tesis 1a. $\mathrm{X} / 2009$, enero de 2009).

Es así, que ante el objetivo que tiene el derecho al mínimo vital, involucra un sinnúmero de medidas estatales de diversa índole (acciones positivas y negativas), cuya finalidad es respetar la dignidad humana en las condiciones prescritas en el artículo 25 de la Constitución mexicana, además de abarcar los derechos de tutela vinculada con la existencia libre, integridad física, vida, protección de la familia y a un mínimo para la supervivencia económica.

A pesar de que el derecho al mínimo vital, no se encuentra consagrado expresamente en la Constitución mexicana, su contenido esencial, es decir, aquello que identifica a este derecho y lo hace reconocible evitando su desaparición o transformación en otra cosa, se colige a partir de la interpretación sistemática de los derechos fundamentales consagrados en sus artículos 10., 30., 40., 6o., 13, 25, 27, 31, fracción IV y 123 constitucionales lo que provoca que el contenido esencial del derecho al mínimo vital comprenda distintas prestaciones básicas para garantizar la subsistencia digna del individuo y de su familia, dentro de las que es posible ubicar a los derechos a la vida, alimentación, vestuario, a la integridad física, educación, vivienda, a la igualdad, a la salud, al trabajo, al medio ambiente y a la seguridad social que protege a todo individuo contra las consecuencias de la vejez y de la incapacidad que lo imposibiliten física o mentalmente para obtener los medios para llevar una vida digna y decorosa.

\section{TEST DE LAS MEDIDAS PARA ABATIR LOS EFECTOS DE LA PANDEMIA POR COVID-19}

Con independencia de la medida que se adopte en el mundo laboral para abatir el desempleo, la disminución de salarios y de las prestaciones, los riesgos profesionales por la pandemia de COVID-19 y el cierre de los centros de trabajo se requiere del intervencionismo del tripartismo (Estado, empleadores y trabajadores).

Los DESCA, como el derecho del trabajo, la seguridad social, la educación, cultura, vivienda, asistencia social, salud y la protección de la familia, no se agotan y captan en una norma abstracta, se requiere de la ineludible intervención de los poderes 
públicos en los ámbitos social y económico, principalmente, a través de políticas públicas y sociales, medidas asistenciales, subsidios a diversas actividades de producción y políticas de creación de cooperativa tendientes a fomentar un estado de paz, bienestar social y nivelación social, además de proteger a los grupos de población social y económicamente desfavorecidos y promover su inclusión, participación activa y goce de sus derechos fundamentales.

En todo caso la implementación de las medidas debe garantizar el contenido esencial de los derechos humanos. Por lo que respecta al derecho al trabajo, su contenido esencial se integra por los siguientes elementos: (Observación 18, 2005)

A. Disponibilidad. Los Estados s deben contar con servicios especializados que tengan por función ayudar y apoyar a los individuos para permitirles identificar el empleo disponible y acceder a él.

B. Accesibilidad. El mercado del trabajo debe poder ser accesible a toda persona que esté bajo la jurisdicción de los Estados. La accesibilidad es tridimensional porque involucra la no discriminación en el acceso al empleo y en su conservación; la accesibilidad física, y la accesibilidad que comprende el derecho de procurar, obtener y difundir información sobre los medios para obtener el acceso al empleo mediante el establecimiento de redes de información sobre el mercado del trabajo en los planos local, regional, nacional e internacional.

C. Aceptabilidad y calidad. La protección del derecho al trabajo es multidimensional porque involucra el derecho del trabajador a condiciones justas, seguras y favorables de trabajo, el derecho a constituir sindicatos y el derecho a elegir y aceptar libremente empleo.

A lo anterior se adiciona el deber de cumplimentar las obligaciones genéricas de respetar, promover, proteger y garantizar el derecho al trabajo y de observar las obligaciones específicas de prevenir, investigar, sancionar, reparar las violaciones a los derechos laborales, y la de aplicar el máximo uso de recursos disponibles, toda vez que la escasez de recursos no libera a los Estados del cumplimiento de las obligaciones mínimas en relación con el ejercicio de los DESCA. Aunque se demuestre que los recursos disponibles son insuficientes, sigue en pie la obligación de que el Estado se empeñe en asegurar el disfrute más amplio posible de los derechos pertinentes dadas las circunstancias reinantes. Más aún, de ninguna manera se eliminan, como resultado de las limitaciones de recursos, las obligaciones de vigilar la medida de la realización, o más especialmente de la no realización de los DESCA y de elaborar estrategias y programas para su promoción (Observación General 3, 1990).

De ser necesaria la afectación o restricción de los derechos humanos ante la pandemia de COVID-19, las medidas que los Estados adopten deben ser temporales, legales y acordes con los objetivos definidos bajo criterios científicos, razonables y proporcionales, teniendo como eje a la dignidad humana y como principios hermenéuticos a la progresividad y la no regresividad. Para determinar si se han adoptado las medidas adecuadas para la realización de los DESCA se deberán conside- 
rar los siguientes aspectos: $a$. Hasta que punto las medidas adoptadas fueron deliberadas, concretas y orientadas al disfrute de los DESCA; b. Si el Estado ejerció sus facultades discrecionales de manera no discriminatoria y sin arbitrariedades; c. Si la decisión del Estado, de no asignar recursos disponibles se ajusta al Derecho Internacional de los Derechos Humanos; d. En caso de que existan varias opciones en materia de normas, si el Estado optó por aquella que menos limita los derechos humanos; e. El factor tiempo en la adopción de las medidas; f) Si las medidas se adoptaron teniendo en cuenta la precaria situación de las personas y los grupos en situación de vulnerabilidad; g. Si las medidas no son discriminatorias y se dio prioridad a las situaciones graves o de riesgo (Corte Interamericana de Derechos Humanos, Caso Acevedo Buendía, 2009), y h. La utilización eficaz, equitativa y la oportunidad de acceder a los recursos disponibles (Principio 27 de Limburgo, 1986).

La información que brinde el Estado sobre la pandemia es una pieza clave para disminuir la transmisión del virus y combatir la desinformación, de igual modo es necesario implementar los servicios adecuados de inspección del trabajo para ver que se cumplan las medidas sanitarias de protección, seguridad y salud en el trabajo para evitar que el trabajador pierda sus ingresos laborales o su trabajo y se tengan que erogar recursos sanitarios para el tratamiento integral del virus, además de cubrirse el correspondiente pago de las prestaciones en dinero para compensar las consecuencias derivadas de la enfermedad que no solo merman la salud, integridad y calidad de vida del operario, sino también representan una de las formas de quebranto de la economía de un país ante la pérdida de tiempo de trabajo, alteraciones de los esquemas productivos, gastos de sustitución y capacitación de empleados, sobrecarga de trabajo para el resto de los operarios y costos para la atención de las demandas laborales interpuestas como resultado de los despidos injustificados, de la falta de reconocimiento y pago de las prestaciones laborales o de su disminución.

Por supuesto, que también corresponde al Estado apoyar a los empleadores, por ejemplo, con la reprogramación del pago de deudas e impuestos y préstamos especiales, pero sobre todo con una reforma fiscal acorde a la situación que prevalece, para salvaguardar las fuentes de trabajo, para que las empresas continúen con sus actividades de manera segura y garanticen el ingreso necesario para sus trabajadores. En este esfuerzo compartido a los trabajadores les corresponde realizar su trabajo con el mayor cuidado y profesionalismo, además de observar las medidas implementadas en el centro laboral para la protección de su vida y salud. Hoy más que nunca, no es el momento para confrontar empleadores con trabajadores, por el contrario, se deben encontrar soluciones conjuntas que provengan del diálogo social entre los factores de la producción.

\section{REFLEXIONES FINALES}

La pandemia ha provocado un sinnúmero de muertes, cambios y afectaciones para la humanidad. El trabajo como un derecho fundamental, que permite la aplicación de otros derechos, este ha sufrido mutaciones, pero sobre todo se ha digitalizado, pues su 
realización ha sido posible gracias a la tecnología. Empleadores y trabajadores han aprendido a vivir en una "nueva normalidad" que ha cambiado en la praxis las reglas laborales y hace necesaria una reforma a la Ley Federal del Trabajo, a pesar de que algunas de sus modificaciones hechas en 2019, no han entrado en vigor en su totalidad.

Hoy en el terreno laboral se hace necesaria la expedición de reglamentos, procedimientos, la implementación de capacitación de sistemas de salud y seguridad en el trabajo que contribuyan a un regreso seguro a la actividad laboral; prioritaria también es la regulación adecuada del teletrabajo que ha venido a ser la tabla de salvación de algunos empleadores y trabajadores, pero sobre todo, es urgente la instauración de los mecanismos necesarios para soslayar la indecencia del trabajo y la inseguridad.

Se plantean distintas propuestas para abatir la precariedad del trabajo, para combatir el desempleo y subempleo, para proteger a los más vulnerables, sin embargo es tiempo de aprender del pasado, visualizar el futuro con todo y lo incierto que se presenta, pero sobre todo, actuar en el presente para analizar las posibles soluciones que beneficien a los empleadores y a los trabajadores, bajo una óptica de derechos humanos que dicta que el derecho al trabajo debe garantizar la dignidad del ser humano, cumplir con los principios de progresividad y no regresividad, respetar los derechos adquiridos, cumplimentar sus obligaciones genéricas y especificas para evitar transgredir su contenido esencial que lo distingue del resto de los derechos humanos.

\section{REFERENCIAS}

1. Alianza Jóvenes con Trabajo Digno. (2020). Hay un aumento del $41 \%$ de jóvenes desempleados. Recuperado de https:/dnf.com.mx/index.php/2020/06/17/jovenes-requieren-mas-empleo-y-mejor-ingreso/

2. AM, 22 de mayo de 2020. Jóvenes resisten al virus, pero no al desempleo, son los más afectados. Recuperado de https://www.am.com.mx/hidalgo/noticias/Jovenes-resisten-al-virus-pero-no-al-desempleo-son-los-mas-afectados-20200522-0001.html

3. Banco de México. (2020). Remesas. Sistema de Información Económica. Recuperado de https://www.banxico.org.mx/SieInternet/consultarDirectorioInternetAction.do? accion $=$ consultarCuadroAnalitico\&idCuadro=CA11\&sector $=1 \&$ locale $=e s$

4. Cámara Mexicana de la Industria de la Construcción. (2020). Recuperado de https://www.cmic.org/category/construccion/

5. Cámara de la Industria de la Transformación de Nuevo León. (2020). Recuperado de https://www.caintra.org.mx/tema-destacado/anuncia-caintra-mas-apoyos-para-las -pymes-industriales/ 
6. Cámara Nacional de Aerotransportes. (2020). Aerolíneas mexicanas perderán al menos 30,000 mdp por el coronavirus. Recuperado de http://canaero.org.mx/noticias/page/39/

7. Cejudo Guillermo, M. (2020), La pandemia como un nuevo motor de desigualdad. Recuperado de https://www.animalpolitico.com/intuiciones-y-evidencia/la-pandemia-como-un-nuevo-motor-de-desigualdad/

8. Centro de Estudios de las Finanzas Públicas. (2020). Indicadores Económicos. Recuperado https://www.cefp.gob.mx/indicadores/gaceta/2020/iescefp0272020.pdf

9. Comisión Económica para América Latina y el Caribe. (2020). Informe intitulado Sectores y empresas frente a la pandemia de COVID-19. Recuperado de https://repositorio.cepal.org/bitstream/handle/11362/45337/S2000264_es.pdf?sequence=6\&isAllow ed $=\mathrm{y}$

10. Comisión Interamericana de Derechos Humanos. (2020). Resolución 1/2020. Recuperado de http://www.oas.org/es/cidh/decisiones/pdf/Resolucion-1-20-es.pdf

11. Comisión Nacional de Acuacultura y Pesca (2020). Recuperado de https://www.gob.mx/conapesca/prensa/adelantara-gobierno-de-mexico- incentivos-del-componente-de-apoyo-para-el-bienestar-de-pescadores-y-acuicultores-bienpesca-239872

12. Comisión Nacional para la Protección y Defensa de los Usuarios de Servicios Financieros. (2020) Diplomado en Educación Financiera.

13. Comité de Derechos Económicos, Sociales y Culturales. Observación General número 3.. Recuperado de https://www.escr-net.org/es/recursos/observacion-general-no-3-indole-obligaciones-estados-partes

14. Comité de Derechos Económicos, Sociales y Culturales. Observación General número 18.. Recuperado de https://www.escr-net.org/es/recursos/observacion-general-no-18-derecho-al-trabajo

15. Comité de Derechos Económicos, Sociales y Culturales. Declaración sobre la pandemia de enfermedad por coronavirus (COVID-19) y los derechos económicos, sociales y culturales. Recuperado de https://jurisprudencia.mpd.gov.ar/Jurisprudencia/Declaraci\%C3\%B3n\%20

sobre $\% 20$ la $\% 20$ pandemia $\% 20$ de $\% 20$ enfermedad $\% 20$ por $\% 20$ coronavirus\%20(COVID-19)\%20y\%20los\%20derechos\%20econ\%C3\%B3micos,\%20sociales\%20 y\%20culturales.pdf.

16. Confederación de Cámaras Industriales de los Estados Unidos Mexicanos. (2020). Recuperado de https://res.cloudinary.com/concamin/image/upload/v1589495332/zvj x7liuxApcan31hf2i.pdf 
17. Conferencia Internacional de Estadísticos. Directrices sobre una definición estadística de empleo informal, adoptadas por la Decimoséptima Conferencia Internacional de Estadísticos del Trabajo (noviembre - diciembre de 2003) Recuperado de https://www.ilo.org/public/spanish/bureau/stat/download/guidelines/defempl.pdf

18. Corte Interamericana de Derechos Humanos (2009). Caso Acevedo Buendía y Otros (“Cesantes y Jubilados de la Contraloría”) vs. Perú. Recuperado de http://www.corteidh.or.cr/docs/casos/articulos/seriec_198_esp.pdf

19. Diario Oficial de Yucatán, 3 de abril de 2020. Recuperado de http://www.yucatan.gob.mx/gobierno/diario_oficial.php?f=2020-4-3

20. Estrella, Viviana, 29 de abril de 2020. Querétaro lanza un programa de apoyos económicos por 240 millones de pesos. El Economista. Recuperado de https://www.eleconomista.com.mx/estados/Queretaro-lanza-un-programa-de-apoyos-econo micos-por-240-millones-de-pesos-20200429-0105.html

21. FORBES. (2020), Recuperación en México tomará hasta 6 años. Recuperado de https://www.forbes.com.mx/economia-recuperacion-mexicotomara-seis-anos -banco-base/

22. García, Ana Karen, 11 de junio de 2020. Actividad industrial cae a mínimo histórico arrastrada por Covid-19, El Economista. Recuperado de https://www.eleconomista.com.mx/empresas/Actividad-industrial-cae-a-minimo-historico-arrastrada-por -Covid-19-20200611-0041.html

23. García Estefan, Luis Carlos. (2020). ¿Contingencia o emergencia sanitaria? Foro jurídico. Recuperado de https://forojuridico.mx/contingencia-o-emergencia-sanitaria/

24. Gobierno de la Ciudad de México. (2020). Apoyo a la economía familiar y microempresarial. Recuperado de https:/www.cdmx.gob.mx/portal/articulo/apoyo-a-laeconomia-familiar-y-microempresarial-por-covid-19

25. Instituto de los Mexicanos en el Exterior. (2018). Estadística de la población mexicana en Estados Unidos. Recuperado de www.ime.gob.mxımundo > america > estados_unidos_details

26. Instituto Mexicano del Seguro Social. (2020). Boletín de prensa. Recuperado de http://www.imss.gob.mx/prensa

27. Instituto Nacional de Estadística y Geografía. (2019). Encuesta Nacional de la Dinámica Demográfica Recuperado de https://www.inegi.org.mx/contenidos/programas/enadid/2018/doc/resultados_enadid18.pdf

28. Instituto Nacional de Estadística y Geografía. (2020). Encuesta Telefónica de Ocupación y Empleo. Recuperado de https://www.inegi.org.mx/investigacion/etoe/ 
29. Instituto Nacional de Estadística y Geografía. (2020). Encuesta Nacional de Ocupación y Empleo. Recuperado de https://www.inegi.org.mx/app/saladeprensa/noticia.html?id=5769

30. México. Suprema Corte de Justicia de la Nación (Primera Sala). Tesis Tesis 1a. XCVII/2007, mayo de 2007.

31. México. Suprema Corte de Justicia de la Nación (Primera Sala). Tesis Tesis 1a. $\mathrm{X} / 2009$, enero de 2009

32. Observatorio de la OIT. (2020). LA COVID 19 y el mundo del trabajo. Cuarta edición Estimaciones actualizadas y análisis. Recuperado de https://www.ilo.org/wcmsp5/groups/public/@dgreports/@dcomm/documents/briefingnote/wcms_745965.pdf

33. Principios de Limburgo sobre la Aplicación del Pacto Internacional de Derechos Económicos, Sociales y Culturales. (1986). Recuperado de http://www.derechos.org. ve/pw/wp-content/uploads/desc_07.pdf

34. Secretaría de Gobernación. (2019). Anuario de migración y remesas México. Recuperado de file:///C:/Users/LENOVO/Downloads/Anuario_Migracion_y_Remesas_ 2019.pdf.

35. Secretaría del Trabajo y Previsión Social, 8 de abril de 2020. Recuperado de https://www.informador.mx/economia/Por-COVID-19-se-han-perdido-346-mil- puestos-de-trabajo-STPS-20200408-0038.html

36. Senado de la República. Recuperado de https://www.senado.gob.mx/64/gaceta_comision_permanente/

37. Solis, Benito, 13 de abril de 2020. El Financiero. Recuperado de https://www.elfinanciero.com.mx/opinion/benito-solis/se-acelera-la-recesion-y-la-perdida-deempleos-en-mexico8.

38. Werner, Alejandro. (2020). Perspectivas para América Latina y el Caribe: La pandemia se intensifica, el Fondo Monetario Internacional. Recuperado de (https://blog-dialogoafondo.imf.org/?p=13682

39. Organización de las Naciones Unidas. (2020). Documento de Políticas: El mundo del trabajo y la COVID-19. Recuperado de https://www.un.org/sites/un2.un.org/files/sg_policy_brief_world_of_work_and_covid_19_spanish.pdf 